\title{
Risk factors for early and delayed post-operative bleeding after endoscopic submucosal dissection of gastric neoplasms, including patients with continued use of antithrombotic agents
}

Tomoaki Matsumura, Makoto Arai, Daisuke Maruoka, Kenichiro Okimoto, Shoko Minemura, Hideaki Ishigami, Keiko Saito, Tomoo Nakagawa, Tatsuro Katsuno and Osamu Yokosuka

\begin{abstract}
Background: Endoscopic submucosal dissection (ESD) has become widely accepted as a standard treatment for gastric epithelial neoplasms. Antithrombotic agents are widely used to prevent thromboembolic disease. However, the feasibility of endoscopic procedures for patients using such agents has been rarely investigated. The aim of this study was to identify risk factors for post-operative bleeding after gastric ESD and to evaluate the relationship between the use of antithrombotic agents and post-operative bleeding.

Methods: From June 2005 to March 2014, 413 patients with 425 gastric neoplasms were treated by ESD. The demographic and clinical parameters associated with post-operative bleeding were investigated. 83 patients receiving antithrombotic agents were separately assessed using various methods of administration during the ESD procedure. Post-operative bleeding that occurred within 5 days of ESD was defined as early post-operative bleeding, whereas subsequent bleeding was defined as delayed bleeding.

Results: The overall post-operative bleeding rate was 4.7\%. In patients with continued low-dose aspirin (LDA), heparin replacement (HR), or continued LDA along with HR, post-operative bleeding rates were $9.5 \%, 23.8 \%$, and $25.0 \%$, respectively. On multivariate analysis, a specimen size of $\geq 40 \mathrm{~mm}$ was a risk factor for early post-operative bleeding [odds ratio (OR) 6.08, 95\% Cl: 1.74-21.27], and HR and chronic kidney disease (CKD) requiring hemodialysis were risk factors for delayed bleeding (OR 12.23, 95\% Cl: 2.63-56.77 and OR 28.35, 95\% Cl: 4.67-172.11, respectively). Continued LDA was not a risk factor for post-operative bleeding.

Conclusions: Large specimen size is a risk factor for early post-operative bleeding, and HR and CKD requiring hemodialysis are risk factors for delayed bleeding. Patients with risk factors should be carefully watched, allowing for the timing of post-operative bleeding after ESD.
\end{abstract}

Keywords: Endoscopic submucosal dissection, ESD, Antithrombotic agents, Post-operative bleeding, Gastric neoplasms, Risk factor

\footnotetext{
*Correspondence: araim-cib@umin.ac.jp

Department of Gastroenterology and Nephrology, Graduate School of

Medicine, Chiba University, Inohana 1-8-1, Chiba-City 260-8670, Japan
} 


\section{Background}

Endoscopic submucosal dissection (ESD) is widely recognized as the optimal treatment for gastric epithelial neoplasms [1-4]. The safety of gastric ESD has been mostly established; however, post-operative bleeding is still the main complication affecting the outcome of the procedure.

Antithrombotic agents are widely used to prevent thromboembolic disease. The number of patients taking antithrombotic agents has increased as a result of increases in the incidence of ischemic heart disease, cerebrovascular disease, and arteriosclerosis obliterans. Although antithrombotic agents are very effective in the management of thromboembolic diseases [5,6], their use increases the incidence of gastrointestinal (GI) bleeding [7-9]. MacQuaid et al. found that low-dose aspirin (LDA) increases the risk of major GI bleeding (relative risk 2.07, 95\% CI: 1.61-2.66) in meta-analysis [8]. In addition, Lanas et al. reported that Helicobacter pylori infection increased the risk of upper GI bleeding in patients taking LDA [10]. On the other hand, endoscopic procedures such as ESD cause post-operative bleeding at a constant rate. Previous studies have reported that the post-operative bleeding rate was approximately $5 \%$ after gastric ESD [11-14]. Because many patients who undergo gastric ESD are infected with Helicobacter pylori, the post-ESD bleeding rate for patients receiving antithrombotic agents is expected to be $>5 \%$.

In clinical practice, healthcare workers need to balance the risks of hemorrhage after endoscopic procedures and thromboembolic events after medication cessation. The American Society for Gastrointestinal Endoscopy (ASGE) guidelines for the management of antithrombotic agents for endoscopic procedures recommend the continued use of LDA for GI endoscopies, even for procedures with a high risk of hemorrhage [15]. In contrast, the European Society of Gastrointestinal Endoscopy (ESGE) guidelines recommend that LDA should be continued for most endoscopies, but discontinued for 5 days prior to ESD and other procedures with a high risk of hemorrhagic complications, provided the risk of thromboembolic events is low [16]. Guidelines for the management of anticoagulant and antiplatelet therapy in patients undergoing endoscopy were published in Japan in 2012 [17,18]. The Japanese guidelines recommend endoscopic procedures without interruption of LDA therapy in patients at high risk of thromboembolic events who use LDA alone. On the other hand, it is recommended that anticoagulants, such as warfarin, can be replaced by heparin as a bridge therapy $[17,18]$. However, there is insufficient data to support these strategies. Furthermore, the risk of bleeding after gastric ESD for patients routinely using LDA remains controversial $[19,20]$. The aim of the present study was to identify risk factors for post-operative bleeding and to evaluate the relationship between the use of antithrombotic agents and post-operative bleeding in patients who underwent ESD for gastric neoplasms.

\section{Methods \\ Patients}

This was a retrospective study. A total of 425 gastric epithelial neoplasms (412 early gastric cancers and 13 gastric adenomas) in 413 patients were treated with ESD at the Chiba University Hospital (Japan) from June 2005 to March 2014. Of the 413 patients, 83 (20.0\%) were on antithrombotic therapy (warfarin potassium in 21 patients, antiplatelet drugs in 62 patients, both warfarin potassium and antiplatelet drugs in 4 patients, and two kinds of antiplatelet drug in 7 patients). All 83 patients were classified into one of two groups, at higher- or lower-risk of thromboembolism, according to risk stratifications based on published criteria $[17,18]$. The high risk of thromboembolism was defined based on the following: two months following coronary artery bare metal stenting; twelve months following coronary artery drug eluting stenting; two months following carotid arterial revascularization (carotid endarterectomy or stenting); ischemic stroke or transient ischemic attack with $>50 \%$ stenosis of major intracranial arteries; recent ischemic stroke or transient ischemic attack; obstructive peripheral artery disease $\geq$ Fontaine grade 3 (rest pain); ultrasonic examination of carotid arteries and magnetic resonance angiography of the head and neck region where withdrawal is considered high risk of thromboembolism; history of cardiogenic brain embolism; atrial fibrillation accompanying valvular heart disease; atrial fibrillation without valvular heart disease but with a high risk of stroke; following mechanical mitral valve replacement; history of thromboembolism following mechanical valve replacement; antiphospholipid antibody syndrome; and deep vein thrombosis/pulmonary thromboembolism $[17,18]$. Of the 46 high-risk patients, 21 continued LDA during the procedures, 21 underwent intravenous heparin replacement (HR), and 4 patients continued LDA and underwent HR. In the 37 low-risk patients, antithrombotic agents were temporarily stopped before the procedures and restarted within 5 days of the procedures (day 1, 3, and 5 after procedures in 26,2 , and 9 patients, respectively).

The indications for ESD were determined on the basis of endoscopic findings, including chromoendoscopy with indigo carmine dye, and biopsy. We referred to the criteria described by Gotoda et al. [1] for possible nodenegative gastric epithelial neoplasia.

\section{ESD procedure}

ESD was performed with a conventional single-channel endoscope (GIF-H260Z or -Q260J; Olympus, Tokyo, Japan) or a two-channel endoscope (2TQ260 M; Olympus). We mainly used an IT knife 2 (KD-611 L; Olympus), 
and electrosurgical current was applied using an electrosurgical generator (VIO 300D; ERBE, T"ubingen, Germany). In addition, we used other electrosurgical knives as necessary, including an IT knife (KD-610 L or KD611 L; Olympus), a Hook knife (KD-620LR; Olympus), or a Flush knife (DK-2618; Fujifilm Inc., Tokyo, Japan), with an ICC200 (ERBE) electrosurgical generator. The injection solutions contained glycerin and hyaluronic acid sodium $(0.4 \%)$ with $1 \%$ indigo carmine dye. The ulcers that developed after ESD were endoscopically examined and any visible vessels were heat-coagulated using hemostatic forceps (FD-410LR; Olympus). The resected specimens were stretched, pinned flat on a corkboard, and measured.

\section{Management after ESD}

Beginning on the day of ESD, omeprazole (40 mg/day) was administered intravenously. From June 2005 to September 2013, we performed second-look endoscopies the day after ESD and coagulated all exposed vessels on artificial ulcers, regardless of whether or not bleeding was present. After October 2013, we did not routinely perform second-look endoscopies. We also checked hemoglobin levels the morning after ESD. If no ESD-related complications occurred, patients were allowed to have a liquid diet. From 2 days after ESD, all patients received 20-mg omeprazole or esomeprazole, and sodium alginate $(120 \mathrm{ml} /$ day $)$ orally. Patients were discharged the day after a diet was established. After discharge, patients were instructed to take 20-mg omeprazole or esomeprazole once a day for 28 days.

\section{Management of patients taking anticoagulants}

When gastric ESD was performed in patients receiving oral anticoagulants such as warfarin, anticoagulants were stopped temporarily 3 days before the procedure and HR was used as a bridge therapy. Unfractionated heparin was used for HR. A continuous administration of heparin was initiated and controlled to keep the activated partial thromboplastin time (APTT) at approximately $60 \mathrm{~s}$. Intravenous $H R$ was stopped $6 \mathrm{~h}$ before ESD. In addition, the prothrombin time international normalized ratio (PT-INR) was measured before ESD to confirm that the drug effect had disappeared. After ESD, intravenous HR was restarted $2 \mathrm{~h}$ after the procedure and oral anticoagulants were restarted the next day after the procedure. Heparin sodium was discontinued when the PT-INR level had reached approximately 1.50 .

\section{Post-operative bleeding}

Post-operative bleeding was defined as a decrease in the blood hemoglobin level of $>2 \mathrm{~g} / \mathrm{dL}$ accompanied by an occurrence of hematemesis, melena, or a combination of unstable vital signs within 4 weeks of ESD. The typical period of hospitalization after ESD was 5 days. Therefore, post-operative bleeding that occurred within 5 days of ESD was defined as early post-operative bleeding, and subsequent bleeding was defined as delayed post-operative bleeding. All patients with post-operative bleeding underwent emergency esophagogastroduodenoscopy (EGD). Information was recorded regarding the time of bleeding and whether any interventions were performed.

\section{Histopathological examination and curability after ESD}

Histopathological examination was based on the 2010 Japanese Classification of Gastric Carcinoma issued by the Japanese Gastric Cancer Association (JGCA) [21]. The entire resected specimen was cut into parallel $2-\mathrm{mm}$ sections and examined with hematoxylin and eosin staining for detailed analysis, including the analysis of the deepest portion containing infiltrating cancer cells. Gastric carcinomas were classified as differentiated or undifferentiated. The former type included well-differentiated tubular adenocarcinoma, moderately differentiated tubular adenocarcinoma, and papillary adenocarcinoma. The latter type included poorly differentiated adenocarcinoma, signet ring cell carcinoma, and mucinous adenocarcinoma. En bloc resection was defined as resection in a single piece. Complete resection was defined as an en bloc resection of a tumor that was shown to be free of cancer cells at both the horizontal and vertical cut ends. The resection was judged as curative when all the following criteria were met: en bloc removal, tumor size $\leq 2 \mathrm{~cm}$, differentiated type, pT1a, negative horizontal margin (HM0), negative vertical margin (VMO), and no lymphovascular infiltration $[$ ly $(-), \mathrm{v}(-)]$. Curative resection for early gastric carcinomas that fell under the expanded indications was defined as follows: en bloc resection, HM0, VM0, ly (-), and $\mathrm{v}(-)$ as well as (1) tumor size $>2 \mathrm{~cm}$, differentiated type, pT1a, and ulceration (UL) $-;$ (2) tumor size $\leq 3 \mathrm{~cm}$, differentiated type, pT1a, and UL +; (3) tumor size $\leq 2 \mathrm{~cm}$, undifferentiated type, pT1a, and UL -; or (4) tumor size $\leq 3 \mathrm{~cm}$, differentiated type, and pT1b (SM1, $\leq 0.5 \mathrm{~mm}$ from the muscularis mucosae) [22].

\section{Statistical analysis}

Some of the patients had more than one gastric neoplasm, and therefore underwent more than one ESD procedure. For statistical purposes, the data from multiple ESD-induced ulcers occurring in certain patients were assumed to constitute independent observations. Baseline data are presented as mean \pm SD. Differences in clinical parameter values between groups were analyzed by unpaired $t$-tests or chi-square tests. The postoperative bleeding rate was established, and the factors associated with post-operative bleeding were assessed using univariate and multivariate analyses. Variables 
with a $P$-value $<0.1$ on univariate analysis were entered into multivariate logistic regression analysis. All statistical analyses were performed using SPSS 20.0 (SPSS Inc., Chicago, IL, USA). A P-value of $<0.05$ was considered statistically significant.

\section{Ethics considerations}

Informed consent was obtained from all patients. The study was conducted in accordance with the Declaration of Helsinki (1995) after the protocol had been approved by the institutional review board of the Chiba University School of Medicine. In addition, this study was registered at the University Hospital Medical Information Network (UMIN000013241).

\section{Results}

\section{Demographic data}

Clinical outcomes are shown in Table 1. The complete en bloc resection rate was $95.1 \%$, perforation rate was $0.5 \%$, and overall post-operative bleeding rate was $4.7 \%$. The clinical characteristics of gastric lesions in patients with gastric neoplasms are shown in Table 2.

\section{Post-operative bleeding}

Twenty patients $(4.7 \%)$ had post-operative bleeding. Table 2 shows clinical differences between patients with post-operative bleeding and those without. In patients with continued LDA, HR, or continued LDA and HR, the post-operative bleeding rates were 9.5\%, 23.8\%, and $25.0 \%$, respectively. In patients with chronic kidney disease (CKD) requiring hemodialysis, the post-operative bleeding rate was $20 \%$. Among all patients with postoperative bleeding patients with $\mathrm{HR}$ and $\mathrm{CKD}$ requiring hemodialysis were significantly more likely to bleed than those without post-operative bleeding $(P<0.05)$. In addition, the maximum diameter of the tumor was significantly larger in patients with post-operative bleeding than those without post-operative bleeding $(P<0.05)$. All the post-operative bleeding occurred within 10 days of ESD. Early and delayed post-operative bleeding occurred in 11 and 9 patients, respectively. In 3 patients,

Table 1 Clinical outcomes of ESD

\begin{tabular}{ll}
\hline Characteristic & \\
\hline Complete en bloc resection (\%) & 95.1 \\
Curability & 72.3 \\
Curative resection (\%) & 21.4 \\
Expanded curative resection (\%) & 6.3 \\
Non-curative resection (\%) & \\
Complication & 0.5 \\
Perforation (\%) & 4.7 \\
\hline Post-operative bleeding (\%)
\end{tabular}

we confirmed post-operative bleeding on second-look endoscopy, and two of them were patients taking antithrombotic agents.

\section{Factors associated with post-operative bleeding}

Table 3 shows univariate and multivariate analyses of the risk factors associated with overall post-operative bleeding. These analyses revealed that $\mathrm{HR}, \mathrm{CKD}$ requiring hemodialysis, and a maximum specimen diameter of $\geq 40 \mathrm{~mm}$ were risk factors for post-operative bleeding [odds ratio (OR) 5.77, 95\% CI: 1.67-19.96; OR 33.86, 95\% CI: 4.72-242.74; and OR 3.70, 95\% CI: 1.09-12.52, respectively]. We repeated the univariate analysis, changing the threshold for specimen size from 30 to $50 \mathrm{~mm}$ in $10 \mathrm{~mm}$ increments. We determined the threshold when the probability value was the lowest and found a specimen size threshold of $40 \mathrm{~mm}$. The maximum diameter of tumor size was strongly correlated to specimen size (Pearson product moment correlation, $r=0.68, P<$ $0.05)$. Therefore, tumor size was excluded from this analysis. The relationship between risk factors and the time of post-operative bleeding is shown in Figure 1. Table 4 shows the univariate analysis of the risk factors associated with early post-operative bleeding. This analysis revealed that a specimen size of $\geq 40 \mathrm{~mm}$ was a risk factor for early post-operative bleeding (OR 6.08, 95\% CI: 1.74-21.27). In contrast, Table 5 shows the univariate and multivariate analyses of the risk factors associated with delayed post-operative bleeding. These analyses revealed that HR and CKD requiring hemodialysis were risk factors for delayed post-operative bleeding (OR 12.23, 95\% CI: 2.63-56.77 and OR 28.35, 95\% CI: 4.67-172.11, respectively). The post-operative bleeding rate was higher in patients with continued LDA. However, there was no statistical association between post-operative bleeding and continued LDA.

\section{Management of post-operative bleeding}

All patients with post-operative bleeding underwent emergency EGD and endoscopic treatment and recovered completely after endoscopic and medical treatment.

\section{Discussion}

In previous guidelines, the cessation of antithrombotic agents during endoscopic procedures was recommended because the emphasis was on the prevention of GI bleeding. However, recently the risks associated with the cessation of such agents have been widely reported [23-26]. Therefore, the management of antithrombotic agents during endoscopic procedures has changed. In Japan, the guidelines were revised in 2012, and endoscopic procedures can be performed without the interruption of LDA therapy in patients at high risk for thromboembolic events $[17,18]$. However, no consensus 
Table 2 Clinical characteristics of gastric lesions in patients with gastric neoplasms

\begin{tabular}{|c|c|c|c|c|}
\hline & $\begin{array}{l}\text { Total } \\
n=425\end{array}$ & $\begin{array}{l}\text { Post-operative bleeding } \\
n=20\end{array}$ & $\begin{array}{l}\text { No post-operative bleeding } \\
n=405\end{array}$ & $p$-value \\
\hline Sex (male/female) & $302 / 123$ & $18 / 2$ & $284 / 121$ & n. S.* \\
\hline Age (years, mean $\pm S D$ ) & $72.1 \pm 8.6$ & $71.9 \pm 10.0$ & $72.1 \pm 8.5$ & n. s. ${ }^{* *}$ \\
\hline \multicolumn{5}{|l|}{ Tumor location (n, \%) } \\
\hline Upper & $65(15)$ & $3(15)$ & $62(15)$ & n. s. ${ }^{*}$ \\
\hline Middle & $179(42)$ & $6(30)$ & $173(43)$ & n. s. ${ }^{*}$ \\
\hline Lower & $181(43)$ & $11(55)$ & $170(42)$ & n. S.* \\
\hline Tumor size (mm, mean \pm SD) & $18.4 \pm 12.6$ & $29.6 \pm 21.8$ & $17.8 \pm 11.7$ & $<0.05^{* *}$ \\
\hline Specimen size $(\mathrm{mm}$, mean $\pm \mathrm{SD})$ & $33.9 \pm 13.3$ & $41.3 \pm 17.6$ & $33.6 \pm 12.9$ & $0.07^{* *}$ \\
\hline \multicolumn{5}{|l|}{ Invasion depth } \\
\hline M & 396 & 18 & 378 & n. S.* \\
\hline SM1 & 15 & 1 & 14 & n. s. ${ }^{*}$ \\
\hline SM2 & 14 & 1 & 13 & n. s. ${ }^{*}$ \\
\hline Ulceration (+/-) & $418 / 7$ & $19 / 1$ & $399 / 6$ & n. S. ${ }^{*}$ \\
\hline \multicolumn{5}{|l|}{ Medication used $(\mathrm{n}, \%)$} \\
\hline Continued use of LDA & $21(9)$ & $2(10)$ & $19(5)$ & n. s. ${ }^{*}$ \\
\hline Continued use of LDA + heparin replacement & $4(1)$ & $1(5)$ & $3(0.7)$ & n. s. ${ }^{*}$ \\
\hline Heparin replacement & $21(5)$ & $5(25)$ & $16(4)$ & $<0.05^{*}$ \\
\hline Cessation of antithrombotic agent during ESD procedure & $41(9)$ & $2(10)$ & $39(10)$ & n. s. ${ }^{*}$ \\
\hline \multicolumn{5}{|l|}{ Comorbidity (n, \%) } \\
\hline Liver cirrhosis & $20(5)$ & $2(10)$ & $18(4)$ & n. S.* \\
\hline CKD undergoing hemodialysis & $20(5)$ & $4(20)$ & $16(4)$ & $<0.05^{*}$ \\
\hline Second-look endoscopy (+/-) & $356 / 69$ & $19 / 1$ & $337 / 68$ & n. s. ${ }^{*}$ \\
\hline
\end{tabular}

LDA: Low-dose aspirin.

CKD: Chronic kidney disease.

${ }^{*}$ Chi-square test.

**Unpaired $t$-test.

n.s.: not significant.

has been reached and controversy exists as to whether the use of these agents is a risk factor for post-operative bleeding after ESD. In previous studies, Koh et al. and Takeuchi et al. reported that the use of antithrombotic drugs was a risk factor for post-operative bleeding after ESD $[27,28]$. However, in these reports, antithrombotic drug therapies were interrupted preoperatively in all patients. In this regard, these studies differed from our research that focused on the continued use of antithrombotic agents and risk factors for post-operative bleeding. On the other hand, Cho et al. also reported an increased risk of bleeding after gastric ESD in a recent study of 19 patients with the continued use of LDA [19]. In contrast, Sanomura et al. reported that the continued use of LDA did not increase the risk of bleeding during or after ESD in 25 patients with the continued use of LDA [20]. In our study, we studied 83 patients and used various methods for administering antithrombotic agents. Our study included 25 patients with the continued use of LDA. The continued use of LDA was not a risk factor but HR, CKD requiring hemodialysis, and a maximum specimen diameter of $\geq 40 \mathrm{~mm}$ were risk factors for post-operative bleeding. In addition, in our study, we evaluated the relationship between risk factors and the time of post-operative bleeding. Large specimen size was a risk factor for early post-operative bleeding, and $\mathrm{HR}$ and CKD requiring hemodialysis were risk factors for delayed bleeding. A temporary cessation of antithrombotic agents during the ESD procedure was not a risk factor for post-operative bleeding.

In previous studies, Kakushima et al. reported that ESDinduced gastric ulcers healed within 8 weeks, regardless of the size and location, and fibrosis and wall thickening were observed from 2 weeks after ESD [29,30]. In addition, Goto et al. reported that visible vessels, which occurred in approximately one quarter of the ulcers within 3 days of ESD, were rarely observed 4 days after ESD [31]. Considering these studies and our results, these visible vessels may cause early post-operative bleeding and may depend on the size of ESD-induced ulcers. In contrast, delayed bleeding may be caused by the delayed healing of ulcers, which in turn may be caused by HR and CKD requiring 
Table 3 Univariate and multivariate analyses of risk factors associated with overall post-operative bleeding

\begin{tabular}{|c|c|c|c|c|}
\hline \multirow[b]{2}{*}{ Risk factor } & \multicolumn{2}{|c|}{ Univariate analysis } & \multicolumn{2}{|c|}{ Multivariate analysis } \\
\hline & OR $(95 \% \mathrm{Cl})$ & $p$-value & OR $(95 \% \mathrm{Cl})$ & $p$-value \\
\hline Male gender (vs. Female) & $3.91(0.89-17.11)$ & $0.07^{*}$ & $6.40(0.69-58.69)$ & 0.10 \\
\hline Age $\geq 70$ years (vs. $\leq 69$ years) & $1.01(0.39-2.58)$ & 0.99 & & \\
\hline Tumor location Lower (vs. Upper and Middle) & $1.65(0.67-4.08)$ & 0.27 & & \\
\hline Continued use of LDA & $2.97(0.81-10.92)$ & 0.10 & & \\
\hline Continued use of LDA + heparin replacement & $6.84(0.68-68.89)$ & 0.10 & & \\
\hline Heparin replacement & $7.99(2.77-22.99)$ & $<0.01^{*}$ & $5.77(1.67-19.96)$ & $0.01^{*}$ \\
\hline Cessation of antithrombotic agent during ESD procedure (vs. No antithrombotic therapy) & $1.82(0.38-8.68)$ & 0.45 & & \\
\hline Liver cirrhosis & $1.51(0.33-6.83)$ & 0.59 & & \\
\hline CKD undergoing hemodialysis & $19.40(4.75-79.19)$ & $<0.01^{*}$ & $33.86(4.72-242.74)$ & $<0.01^{*}$ \\
\hline Specimen size $\geq 40 \mathrm{~mm}$ (vs. $<40 \mathrm{~mm}$ ) & $2.84(1.14-7.09)$ & $0.03^{*}$ & $3.70(1.09-12.52)$ & $0.04^{*}$ \\
\hline Procedure time $\geq 90 \mathrm{~min}$ (vs. $<90 \mathrm{~min}$ ) & $3.05(1.12-8.29)$ & $0.03^{*}$ & $2.45(0.74-8.16)$ & 0.15 \\
\hline Second-look endoscopy (vs. No second-look endoscopy) & $3.83(0.51-29.14)$ & 0.19 & & \\
\hline
\end{tabular}

OR: Odds ratio.

$\mathrm{Cl}$ : Confidence interval.

LDA: Low-dose aspirin.

CKD: Chronic kidney disease.

${ }^{*} p<0.05$.

hemodialysis. Yoshio et al. reported that gastric ESD under HR was associated with a high risk of postoperative bleeding (37.5\%), a finding that was similar to the result in our study (23.8\%) [32]. These high incidences of post-operative bleeding may be caused using two kinds of anticoagulant therapy (oral anticoagulants and intravenous heparin) from the day after ESD. We routinely performed second-look endoscopy before September 2013. However, in a prospective, randomized, controlled study, Ryu et al. found that second-look endoscopy was not associated with clinical outcomes including bleeding and morbidity after gastric ESD [33]. For this reason, we did not perform second-look endoscopy routinely after October 2013. In the present study,

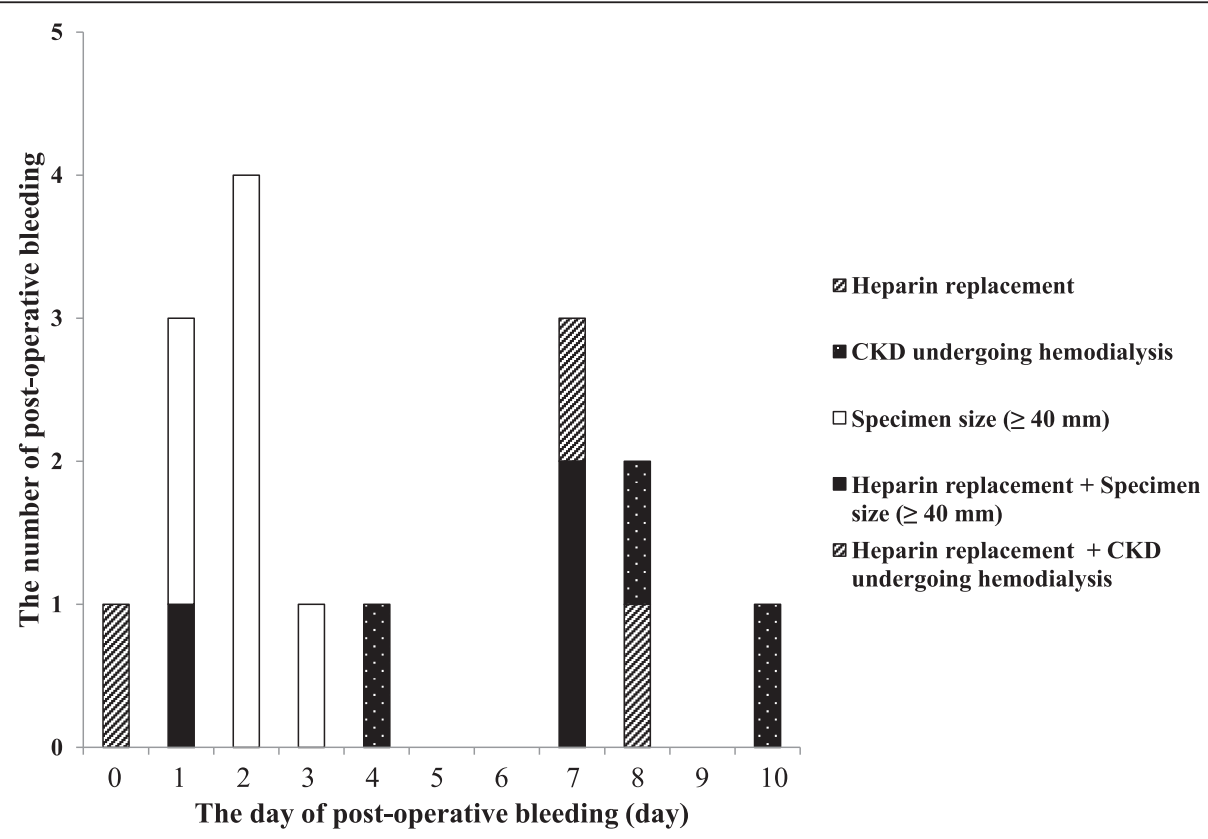

Figure 1 The relationship between the time of post-ESD bleeding and risk factors: most cases of post-operative bleeding in patients with specimen size $\geq \mathbf{4 0} \mathbf{m m}$ occurred within $\mathbf{5}$ days of ESD. On the other hand, most cases of post-operative bleeding in patients with one or more risk factors occurred after 6 days after ESD. 
Table 4 Univariate and multivariate analyses of risk factors associated with early post-operative bleeding

\begin{tabular}{|c|c|c|c|c|}
\hline \multirow[b]{2}{*}{ Risk factor } & \multicolumn{2}{|l|}{ Univariate analysis } & \multicolumn{2}{|c|}{ Multivariate analysis } \\
\hline & OR $(95 \% \mathrm{Cl})$ & $p$-value & OR $(95 \% \mathrm{Cl})$ & $p$-value \\
\hline Male gender (vs. Female) & $4.25(0.53-33.61)$ & 0.17 & & \\
\hline Age $\geq 70$ years (vs. $\leq 69$ years) & $1.45(0.38-5.57)$ & 0.58 & & \\
\hline Tumor location Lower (vs. Upper and Middle) & $2.36(0.68-8.20)$ & 0.17 & & \\
\hline Continued use of LDA & $3.66(0.74-17.93)$ & 0.11 & & \\
\hline Continued use of LDA + heparin replacement & $13.30(1.27-139.25)$ & $0.03^{*}$ & $32.88(2.61-414.05)$ & $<0.01^{*}$ \\
\hline Heparin replacement & $3.50(0.71-17.10)$ & 0.12 & & \\
\hline Cessation of antithrombotic agent during ESD procedure (vs. No antithrombotic therapy) & $3.08(0.60-15.87)$ & 0.18 & & \\
\hline Liver cirrhosis & $1.33(0.16-10.81)$ & 0.78 & & \\
\hline CKD undergoing hemodialysis & $4.92(0.56-43.20)$ & 0.15 & & \\
\hline Specimen size $\geq 40 \mathrm{~mm}$ (vs. $<40 \mathrm{~mm}$ ) & $6.08(1.74-21.27)$ & $<0.01^{*}$ & $8.03(2.03-31.72)$ & $<0.01^{*}$ \\
\hline Procedure time $\geq 90 \mathrm{~min}$ (vs. $<90 \mathrm{~min}$ ) & $3.44(0.81-14.71)$ & 0.10 & & \\
\hline Second-look endoscopy (vs. No second-look endoscopy) & $1.96(0.24-15.60)$ & 0.52 & & \\
\hline
\end{tabular}

OR: Odds ratio.

Cl: Confidence interval.

LDA: Low-dose aspirin.

CKD: Chronic kidney disease.

${ }^{*} p<0.05$.

we also analyzed the relationship between second-look endoscopy and post-operative bleeding. There was no statistical association between post-operative bleeding and second-look endoscopy.

There are several limitations to this study. First, the study was a retrospective study and was conducted at a single center. Second, this study contained a small number of cases with the continued use of antithrombotic agents. Third, the number of patients with post-operative bleeding was small. These limitations indicate that our study requires further validation. In addition, the cessation of antithrombotic agents in patients at high risk of thromboembolism is difficult in view of the risks associated with the cessation of such agents. Therefore, we could not perform a randomized controlled study that stratified patients on the basis of the risk of thromboembolism. In the future, further research involving large numbers of patients is warranted.

\section{Table 5 Univariate and multivariate analyses of risk factors associated with delayed post-Operative bleeding}

\begin{tabular}{|c|c|c|c|c|}
\hline \multirow[b]{2}{*}{ Risk factor } & \multicolumn{2}{|l|}{ Univariate analysis } & \multicolumn{2}{|c|}{ Multivariate analysis } \\
\hline & OR $(95 \% \mathrm{Cl})$ & $p$-value & OR $(95 \% \mathrm{Cl})$ & $p$-value \\
\hline Male gender (vs. Female) & $3.38(0.41-27.32)$ & 0.25 & & \\
\hline Age $\geq 70$ years (vs. $\leq 69$ years) & $0.67(0.17-2.53)$ & 0.55 & & \\
\hline Tumor location Lower (vs. Upper and Middle) & $1.05(0.28-3.99)$ & 0.55 & & \\
\hline Continued use of LDA & $1.98(0.23-16.4)$ & 0.52 & & \\
\hline Continued use of LDA + heparin replacement & N/A & N/A & & \\
\hline Heparin replacement & $13.89(3.48-55.39)$ & $<0.01^{*}$ & $12.23(2.63-56.77)$ & $<0.01^{*}$ \\
\hline Cessation of antithrombotic agent during ESD procedure (vs. No antithrombotic therapy) & N/A & N/A & & \\
\hline Liver cirrhosis & $1.67(0.20-13.9)$ & 0.63 & & \\
\hline CKD undergoing hemodialysis & $33.16(6.67-164.82)$ & $<0.01^{*}$ & $28.35(4.67-172.11)$ & $<0.01^{*}$ \\
\hline Specimen size $\geq 40 \mathrm{~mm}$ (vs. $<40 \mathrm{~mm}$ ) & $0.92(0.19-4.55)$ & 0.92 & & \\
\hline Procedure time $\geq 90 \mathrm{~min}$ (vs. $<90 \mathrm{~min}$ ) & $2.56(0.67-9.78)$ & 0.16 & & \\
\hline Second-look endoscopy (vs. No second-look endoscopy) & N/A & N/A & & \\
\hline
\end{tabular}

OR: Odds ratio.

$\mathrm{Cl}$ : Confidence interval.

LDA: Low-dose aspirin.

CKD: Chronic kidney disease.

$\mathrm{N} / \mathrm{A}$ : Not applicable.

${ }^{*} p<0.05$. 


\section{Conclusions}

Large specimen size is a risk factor for early post-operative bleeding, and HR and CKD requiring hemodialysis are risk factors for delayed bleeding. In contrast, continued LDA is not a risk factor for post-operative bleeding. Patients with risk factors should be carefully watched, allowing for the timing of post-operative bleeding after ESD.

\section{Abbreviations}

ESD: Endoscopic submucosal dissection; CKD: Chronic kidney disease;

LDA: Low-dose aspirin; HR: Heparin replacement;

EGD: Esophagogastroduodenoscopy; APTT: Activated partial thromboplastin time.

\section{Competing interests}

The authors declare that they have no competing interest.

\section{Authors' contributions}

TM, DM and MA planned the study. TM and MA performed the statistical analysis and drafted the manuscript. TK and OY conducted the study. TM, $\mathrm{DM}, \mathrm{KO}, \mathrm{SM}, \mathrm{HI}, \mathrm{KS}$ and TN corrected the data. All authors read and approved the final manuscript.

\section{Acknowledgements}

The authors would like to thank the staff of the Endoscopy Unit of Chiba University Hospital for technical assistance and documentation in performing the study.

Received: 10 June 2014 Accepted: 24 September 2014 Published: 3 October 2014

\section{References}

1. Gotoda T, Yanagisawa A, Sasako M, Ono H, Nakanishi Y, Shimoda T, Kato Y: Incidence of lymph node metastasis from early gastric cancer: estimation with a large number of cases at two large centers. Gastric Cancer 2000, 3:219-225.

2. Fujishiro M, Yahagi N, Nakamura M, Kakushima N, Kodashima S, Ono S, Kobayashi K, Hashimoto T, Yamamichi N, Tateishi A, Shimizu Y, Oka M, Ogura K, Kawabe T, Ichinose M, Omata M: Successful outcomes of a novel endoscopic treatment for Gl tumors: endoscopic submucosal dissection with a mixture of high-molecular-weight hyaluronic acid, glycerin, and sugar. Gastrointest Endosc 2006, 63:243-249.

3. Oka S, Tanaka S, Kaneko I, Mouri R, Hirata M, Kawamura T, Yoshihara M, Chayama K: Advantage of endoscopic submucosal dissection compared with EMR for early gastric cancer. Gastrointest Endosc 2006, 64:877-883.

4. Nakamoto S, Sakai Y, Kasanuki J, Kondo F, Ooka Y, Kato K, Arai M, Suzuki T, Matsumura T, Bekku D, Ito K, Tanaka T, Yokosuka O: Indications for the use of endoscopic mucosal resection for early gastric cancer in Japan: a comparative study with endoscopic submucosal dissection. Endoscopy 2009, 41:746-750.

5. Antithrombotic Trialists' Collaboration: Collaborative meta-analysis of randomised trials of antiplatelet therapy for prevention of death, myocardial infarction, and stroke in high risk patients. BMJ 2002, 324(7329):71-86.

6. Hart RG, Pearce LA, Aguilar MI: Meta-analysis: antithrombotic therapy to prevent stroke in patients who have nonvalvular atrial fibrillation. Ann Intern Med 2007, 146:857-867.

7. Laine L: Review article: gastrointestinal bleeding with low-dose aspirin - what's the risk? Aliment Pharmacol Ther 2006, 24:897-908.

8. McQuaid KR, Laine L: Systematic review and meta-analysis of adverse events of low-dose aspirin and clopidogrel in randomized controlled trials. Am J Med 2006, 119:624-638.

9. Antithrombotic Trialists' (ATT) Collaboration, Baigent C, Blackwell L, Collins R, Emberson J, Godwin J, Peto R, Buring J, Hennekens C, Kearney P, Meade T, Patrono C, Roncaglioni MC, Zanchetti A: Aspirin in the primary and secondary prevention of vascular disease: collaborative meta-analysis of individual participant data from randomised trials. Lancet 2009 373:1849-1860
10. Lanas A, Fuentes J, Benito R, Serrano P, Bajador E, Sáinz R: Helicobacter pylori increases the risk of upper gastrointestinal bleeding in patients taking low-dose aspirin. Aliment Pharmacol Ther 2002, 16:779-786.

11. Goto O, Fujishiro M, Oda I, Kakushima N, Yamamoto Y, Tsuji Y, Ohata K, Fujiwara T, Fujiwara J, Ishii N, Yokoi C, Miyamoto S, Itoh T, Morishita S, Gotoda T, Koike K: A multicenter survey of the management after gastric endoscopic submucosal dissection related to postoperative bleeding. Dig Dis Sci 2012, 57:435-439.

12. Watanabe K, Ogata S, Kawazoe S, Watanabe K, Koyama T, Kajiwara T, Shimoda Y, Takase Y, Irie K, Mizuguchi M, Tsunada S, Iwakiri R, Fujimoto K: Clinical outcomes of EMR for gastric tumors: historical pilot evaluation between endoscopic submucosal dissection and conventional mucosal resection. Gastrointest Endosc 2006, 63:776-782.

13. Takizawa K, Oda I, Gotoda T, Yokoi C, Matsuda T, Saito Y, Saito D, Ono H: Routine coagulation of visible vessels may prevent delayed bleeding after endoscopic submucosal dissection and analysis of risk factors. Endoscopy 2008, 40:179-183.

14. Ono S, Fujishiro M, Niimi K, Goto O, Kodashima S, Yamamichi N, Omata M: Technical feasibility of endoscopic submucosal dissection for early gastric cancer in patients taking anti-coagulants or anti-platelet agents. Dig Liver Dis 2009, 41:725-728.

15. Anderson MA, Ben-Menachem T, Gan SI, Gan SI, Appalaneni V, Banerjee S, Cash BD, Fisher L, Harrison ME, Fanelli RD, Fukami N, Ikenberry SO, Jain R, Khan K, Krinsky ML, Lichtenstein DR, Maple JT, Shen B, Strohmeyer L, Baron $\mathrm{T}$, Dominitz JA: Management of antithrombotic agents for endoscopic procedures. Gastrointest Endosc 2009, 70:1060-1070.

16. Boustière $C$, Veitch $A$, Vanbiervliet $G$, Bulois $P$, Deprez $P$, Laquiere $A$, Laugier R, Lesur G, Mosler P, Nalet B, Napoleon B, Rembacken B, Ajzenberg N, Collet $J P$, Baron T, Dumonceau JM, European Society of Gastrointestinal Endoscopy: Endoscopy and antiplatelet agents. European Society of Gastrointestinal Endoscopy (ESGE) guideline. Endoscopy 2011, 43:445-461.

17. Fujimoto K, Fujishiro M, Katou M, Higuchi K, Iwakiri R, Sakamoto C, Uchiyama S, Kashiwagi A, Ogawa H, Murakami K, Mine T, Yoshino J, Kinoshita Y, Ichinose M, Matsui T: Guidelines for gastroenterological endoscopy in patients undergoing antithrombotic treatment. Gastroenterol Endosc 2012, 54:2073-2102 (in Japanese).

18. Fujimoto K, Fujishiro M, Kato M, Higuchi K, Iwakiri R, Sakamoto C, Uchiyama S, Kashiwagi A, Ogawa H, Murakami K, Mine T, Yoshino J, Kinoshita Y, Ichinose M, Matsui T: Guidelines for gastroenterological endoscopy in patients undergoing antithrombotic treatment. Dig Endosc 2014, 26:1-14.

19. Cho SJ, Choi IJ, Kim CG, Lee JY, Nam BH, Kwak MH, Kim HJ, Ryu KW, Lee JH, Kim YW: Aspirin use and bleeding risk after endoscopic submucosal dissection in patients with gastric neoplasms. Endoscopy 2012, 44:114-121.

20. Sanomura Y, Oka S, Tanaka S, Numata N, Higashiyama M, Kanao H, Yoshida S, Ueno Y, Chayama K: Continued use of low-dose aspirin does not increase the risk of bleeding during or after endoscopic submucosal dissection for early gastric cancer. Gastric Cancer 2014, 17:489-496.

21. Japanese Gastric Cancer Association: Japanese classification of gastric carcinoma: 3rd English edition. Gastric Cancer 2011, 14:101-112.

22. Japanese Gastric Cancer Association: Japanese gastric cancer treatment guidelines 2010 (ver. 3). Gastric Cancer 2011, 14:113-123.

23. Sung JJ, Lau JY, Ching JY, Wu JC, Lee YT, Chiu PW, Leung VK, Wong WW, Chan FK: Continuation of low-dose aspirin therapy in peptic ulcer bleeding: a randomized trial. Ann Intern Med 2010, 152:1-9.

24. Maulaz AB, Bezerra DC, Michel P, Bogousslavsky J: Effect of discontinuing aspirin therapy on the risk of brain ischemic stroke. Arch Neurol 2005, 62:1217-1220.

25. Biondi-Zoccai GG, Lotrionte M, Agostoni P, Abbate A, Fusaro M, Burzotta F, Testa L, Sheiban I, Sangiorgi G: A systematic review and meta-analysis on the hazards of discontinuing or not adhering to aspirin among 50,279 patients at risk for coronary artery disease. Eur Heart J 2006, 27:2667-2674

26. Sibon I, Orgogozo JM: Antiplatelet drug discontinuation is a risk factor for ischemic stroke. Neurology 2004, 62:1187-1189.

27. Koh R, Hirasawa K, Yahara S, Oka H, Sugimori K, Morimoto M, Numata K, Kokawa A, Sasaki T, Nozawa A, Taguri M, Morita S, Maeda S, Tanaka K: Antithrombotic drugs are risk factors for delayed postoperative bleeding after endoscopic submucosal dissection for gastric neoplasms. Gastrointest Endosc 2013, 78:476-483.

28. Takeuchi T, Ota K, Harada S, Edogawa S, Kojima Y, Tokioka S, Umegaki E, Higuchi $K$ : The postoperative bleeding rate and its risk factors in patients 
on antithrombotic therapy who undergo gastric endoscopic submucosal dissection. BMC Gastroenterol 2013, 13:136.

29. Kakushima N, Yahagi N, Fujishiro M: The healing process of gastric artificial ulcers after endoscopic submucosal dissection. Dig Endosc 2004, 16:327-331

30. Kakushima N, Fujishiro M, Kodashima S, Kobayashi K, Tateishi A, Iguchi M, Imagawa A, Motoi T, Yahagi N, Omata M: Histopathologic characteristics of gastric ulcers created by endoscopic submucosal dissection. Endoscopy 2006, 38:412-415.

31. Goto O, Fujishiro M, Kodashima S, Minatsuki C, Niimi K, Ono S, Yamamichi N, Koike K: Short-Term Healing Process of Artificial Ulcers after Gastric Endoscopic Submucosal Dissection. Gut Liver 2011, 5:293-297.

32. Yoshio T, Nishida T, Kawai N, Yuguchi K, Yamada T, Yabuta T, Komori M, Yamaguchi S, Kitamura S, lijima H, Tsutsui S, Michida T, Mita E, Tsujii M, Takehara T: Gastric ESD under Heparin Replacement at High-Risk Patients of Thromboembolism Is Technically Feasible but Has a High Risk of Delayed Bleeding: Osaka University ESD Study Group. Gastroenterol Res Pract 2013, 2013:365830.

33. Ryu HY, Kim JW, Kim HS, Park HJ, Jeon HK, Park SY, Kim BR, Lang CC, Won SH: Second-look endoscopy is not associated with better clinical outcomes after gastric endoscopic submucosal dissection: a prospective, randomized, clinical trial analyzed on an as-treated basis. Gastrointest Endosc 2013, 78:285-294

doi:10.1186/1471-230X-14-172

Cite this article as: Matsumura et al:: Risk factors for early and delayed post-operative bleeding after endoscopic submucosal dissection of gastric neoplasms, including patients with continued use of antithrombotic agents. BMC Gastroenterology 2014 14:172.

\section{Submit your next manuscript to BioMed Central and take full advantage of:}

- Convenient online submission

- Thorough peer review

- No space constraints or color figure charges

- Immediate publication on acceptance

- Inclusion in PubMed, CAS, Scopus and Google Scholar

- Research which is freely available for redistribution 